\title{
Grass-Like Mantid, American Grass Mantid, Thesprotia graminis, (Scudder, 1878) (Insecta: Mantodea: Thespidae) ${ }^{1}$
}

\author{
Bethany McGregor, Nathan Burkett-Cadena, and Andrea Lucky²
}

\section{Introduction}

Praying mantids are charismatic insects that are considered beneficial to humans because of their insectivorous lifestyle and because of their aesthetic appeal. Despite this, many praying mantid species remain understudied. One species that occurs in the southeastern United States is the grasslike mantid, Thesprotia graminis (Scudder) (Figure 1). This small, cryptic mantid species is light brown to green in color and can easily blend in with pine needles and grass, making it difficult to detect in its natural habitat.

Although this mantid may be mistaken for a stick insect (Order: Phasmatodea), especially when its forelegs are held directly in front of the body and it resembles a blade of grass, the raptorial forelimbs reveal the insect's true identity. There are 14 Neotropical species within the genus Thesprotia, all of which occur in South America except Thesprotia graminis (Rondon et al. 2007). The type specimen for this species is a male that was collected in Gainesville, Florida. It is vouchered in the entomology collection of the Academy of Natural Sciences in Philadelphia, Pennsylvania.

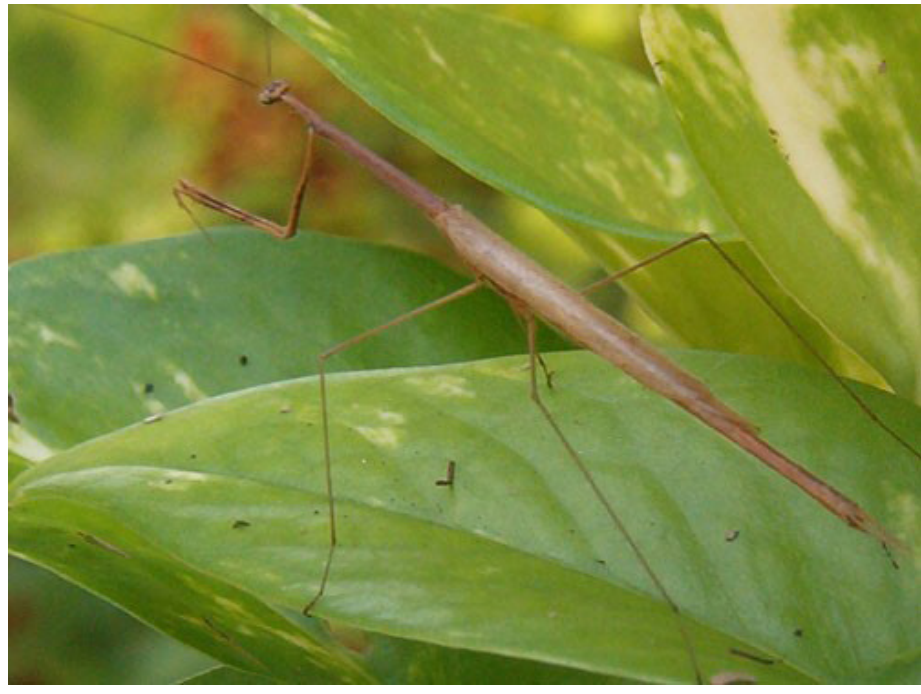

Figure 1. Adult male Thesprotia graminis (Scudder).

Credits: Nathan Burkett-Cadena, UF/IFAS

\section{Synonymy}

Oligonyx graminis Scudder, 1878 (Rondon et al. 2007). This species was previously classified as belonging to the family Mantidae (Rehn and Hebard 1904), but has since been transferred to the family Thespidae (Patel et al. 2016).

1. This document is EENY-719, one of a series of the Entomology and Nematology Department, UF/IFAS Extension. Original publication date January 2019. Visit the EDIS website at https://edis.ifas.ufl.edu for the currently supported version of this publication. This document is also available on the Featured Creatures website at http://entnemdept.ifas.ufl.edu/creatures/.

2. Bethany McGregor; Nathan Burkett-Cadena, and Andrea Lucky, assistant professors; Entomology and Nematology Department; UF/IFAS Extension, Gainesville, FL 32611

The Institute of Food and Agricultural Sciences (IFAS) is an Equal Opportunity Institution authorized to provide research, educational information and other services

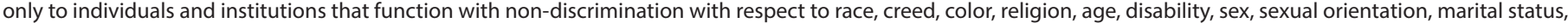

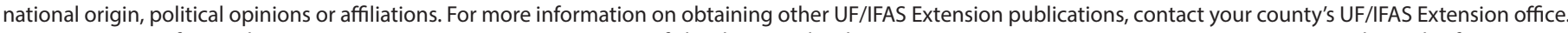
U.S. Department of Agriculture, UF/IFAS Extension Service, University of Florida, IFAS, Florida A \& M University Cooperative Extension Program, and Boards of County Commissioners Cooperating. Nick T. Place, dean for UF/IFAS Extension. 


\section{Distribution}

This species occurs in the extreme southeastern United States with many records throughout Florida (HughesSchrader 1953) as far south as Key West (Rehn and Hebard 1914). It has also been recorded in Georgia and Mississippi (Patel et al. 2016, Peck and Beninger 1989).

\section{Description}

Mantids are hemimetabolous insects that undergo three life stages: egg, nymph (juvenile), and adult.

Eggs: Eggs are laid in small egg cases called oothecae (Figures 2 and 3). The female deposits a frothy material into which she places two rows of eggs. After deposition, the froth hardens, forming a protective structure that guards against predators and is largely weather resistant (PrestonMafham 1990).

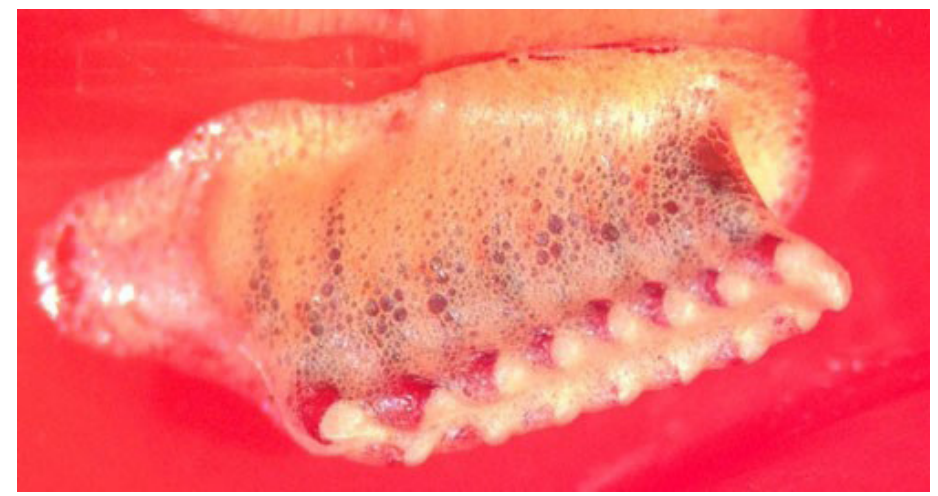

Figure 2. Close up view of the structure of the ootheca of Thesprotia graminis (Scudder).

Credits: Bethany McGregor, UF/IFAS

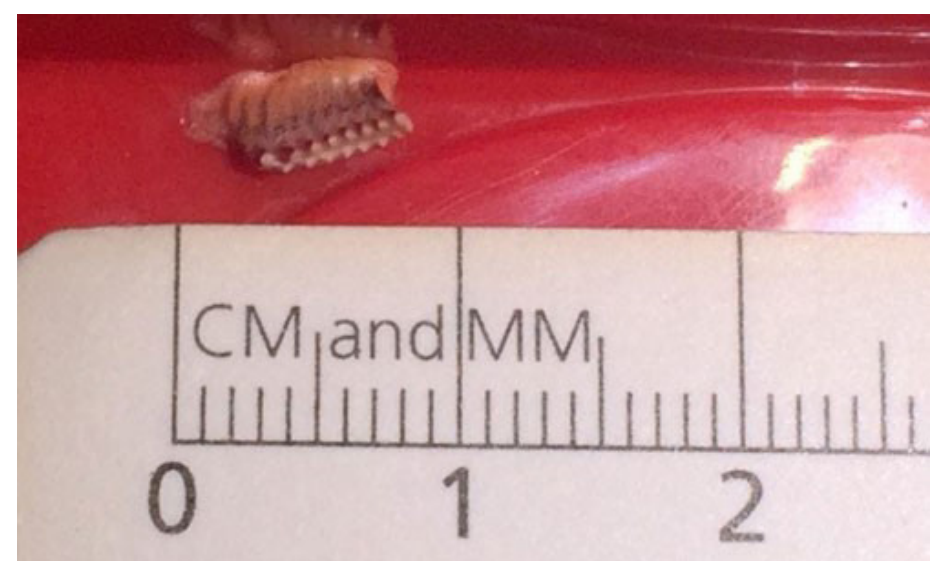

Figure 3. Ootheca of Thesprotia graminis (Scudder) laid on the lid of a collecting container. A ruler is shown alongside the ootheca to indicate the size, which is roughly $8 \mathrm{~mm}$ in length.

Credits: Bethany McGregor, UF/IFAS
Nymphs: Nymphs resemble smaller versions of adults in their light brown to green color, but lack functional reproductive organs and wings at this stage (Whitfield and Purcell 2014). The first instar (life stage) is a very short-lived, non-feeding stage. From the second instar, the nymph can begin hunting and consuming food (Whitfield and Purcell 2014). During the earliest instars the nymphs of some mantid species may superficially resemble ants, which may function as a form of protective mimicry (Preston-Mafham 1990). However, the extremely elongate body of Thesprotia graminis nymphs are more slender and less ant-like than other species (Figure 4).

Nymphs and adults have a specialized hearing apparatus consisting of two tympana located in a groove on the ventral side of the metathorax. In some mantid species, this ear like structure can be a sexually dimorphic characteristic, with the tympana of winged males being larger and better developed than that of the flightless females. In some species females may lack this structure entirely (Yager 1990). The auditory capability of the two sexes has not yet been studied in Thesprotia graminis.

In this species, the number of nymphal instars differs between the sexes, with females undergoing seven molts, on average, and males only six. Adult males possess functional wings, whereas adult females do not; this makes distinguishing late instar Thesprotia graminis nymphs from adult females challenging.

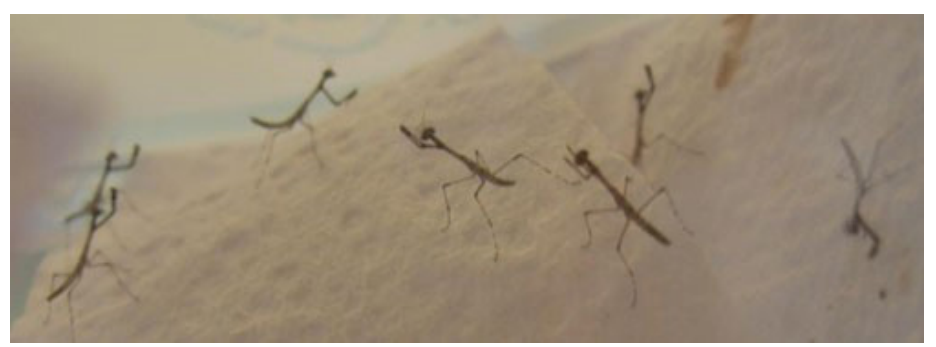

Figure 4. Thesprotia graminis (Scudder) nymphs raised in captivity. Note the elongate body shape and the characteristic posture with the abdomen somewhat curled dorsally.

Credits: Yen Saw, usamantis.com

Adults: Adult Thesprotia graminis generally range between 47 and $56 \mathrm{~mm}$ in length (Figure 5), although much larger specimens have been collected, including a female from Punta Gorda, Florida that was $60.5 \mathrm{~mm}$ in length (Rehn and Hebard 1914). Adult females lack wings, which is not uncommon in this mantid family (Rivera 2010). The males, in contrast, have well developed wings and are very capable flyers (Figure 1). Both sexes are light brown in color and have very slender bodies. 


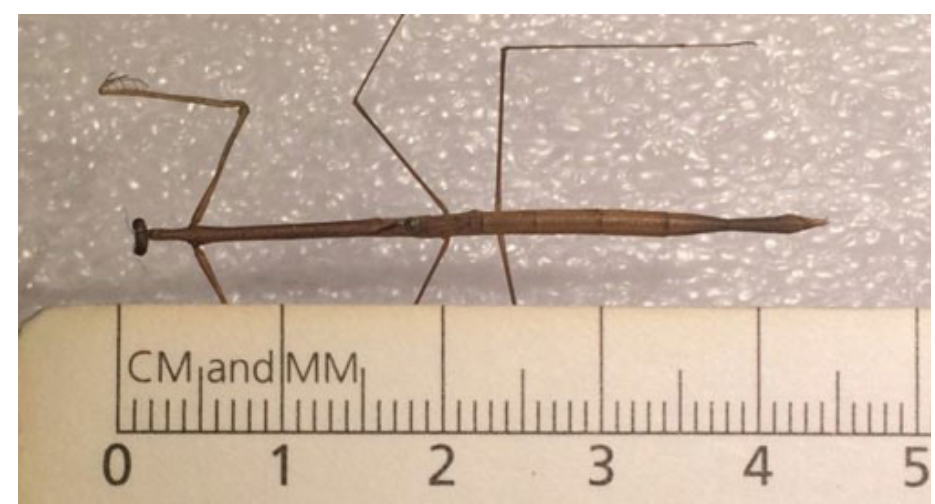

Figure 5. Adult female Thesprotia graminis (Scudder) shown alongside a ruler. This specimen measures about $44 \mathrm{~mm}$ in length, which is just short of the average length range for the species.

This could be due to the effect of drying on the specimen.

Credits: Bethany McGregor, UF/IFAS

The antennae are approximately $23 \mathrm{~mm}$ long (Scudder 1877), although male antennae tend to be longer than female antennae (Helfer 1953). The head is approximately triangular, with small black spots on ridges above the eyes. The two corners at the top of the head terminate in upwardpointing projections (Figure 6) (Scudder 1877). One of the main diagnostic characteristics for this species is the length of the posterior portion of the pronotum which begins just behind the forelegs and is 3 to 4 times longer than the anterior portion (Figure 7). The foretibiae are also distinctive in this species, having relatively few teeth present but with at least one single large dorsal spine (Figure 8).

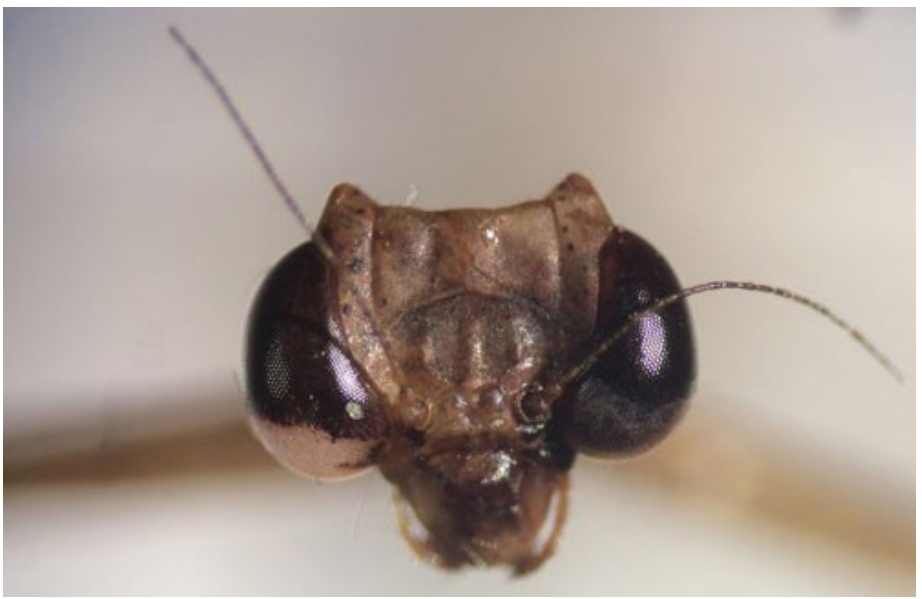

Figure 6. The head of Thesprotia graminis (Scudder) showing the characteristic triangular shape and sparse black spots.

Credits: Bethany McGregor, UF/IFAS

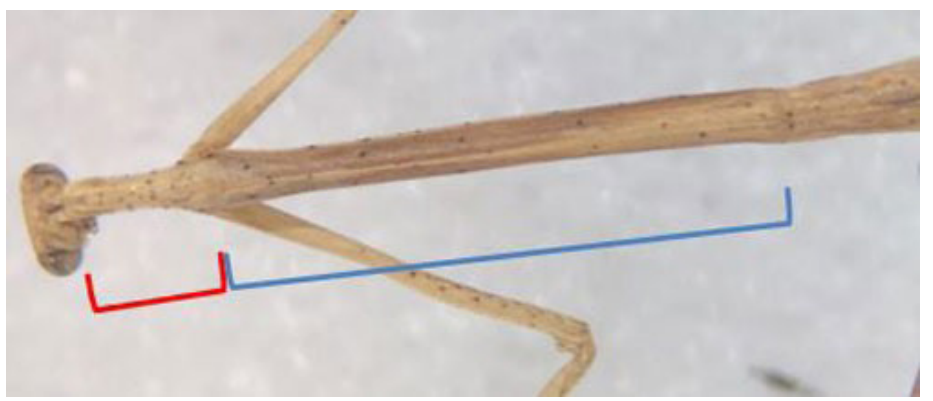

Figure 7. Pronotum length of an adult female Thesprotia graminis (Scudder). Note the posterior portion (blue) of the pronotum is more than 3 to 4 times as long as the anterior portion (red).

Credits: Bethany McGregor, UF/IFAS

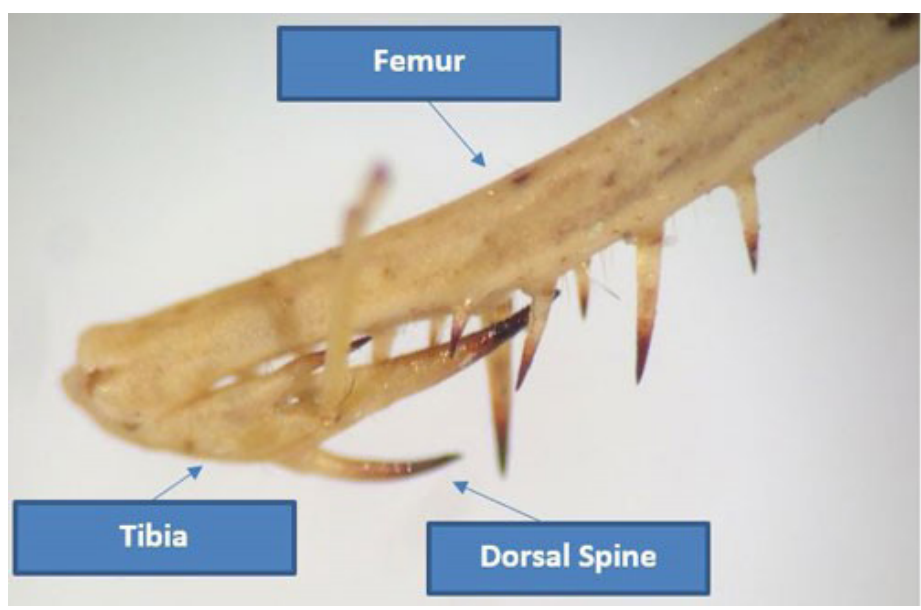

Figure 8. Foreleg of Thesprotia graminis (Scudder) showing the femur with many spines and the small tibia possessing few spines, but with a single large dorsal spine, which is characteristic of this species. The tarsus is out of focus in this picture. Credits: Bethany McGregor, UF/IFAS

\section{Life Cycle}

Females of this species can reproduce either sexually or asexually through parthenogenesis. Offspring produced through parthenogenesis are always female. The oothecae in (Figure 2) was laid parthenogenetically, which is a sexual strategy that allows females to reproduce even if mates are unavailable. Sexual cannibalism, where the female ingests the male after or during mating, is seen frequently within the Mantodea; however, it is unknown whether this species exhibits this behavior (Holwell 2006).

Most temperate mantid species overwinter as eggs, with the first instar nymphs hatching in the spring (Whitfield and Purcell 2014). However, after hatching, there is some variation in periodicity throughout the year. Nymphs of this species have been recovered in nature alongside adults, indicating that there is no definitive periodicity because maturation and growth continues throughout the warm periods of the year (Rehn and Hebard 1914). 


\section{Hosts}

The hunting and feeding practices of mantids are reflected in their common name. Mantids hunt their prey using a sit-and-wait ambush technique. While sitting in wait for prey, most mantid species will hold their raptorial forelegs in front of them in what is commonly called a praying position. The femur and tibia of the forelimb are often covered in spines to aid in prey capture, and the cryptic coloration of the mantids provides camouflage for catching prey as well as for avoiding larger predators (Preston-Mafham 1990).

Mantids have been documented feeding on a variety of organisms including flies, moths, small grasshoppers and crickets, beetles, true bugs, spiders, and even other mantids (Preston-Mafham 1990). However, mantid diets are not restricted to invertebrates. Other members of the same family, Thespidae, to which Thesprotia graminis belongs, have been documented consuming treefrogs in Brazil (Costa-Pereira et al. 2010). Due to the relatively thin body of Thesprotia graminis it is unlikely to take any large vertebrate prey, but adults will readily feed on large flies or small to medium sized moths (Figure 9).

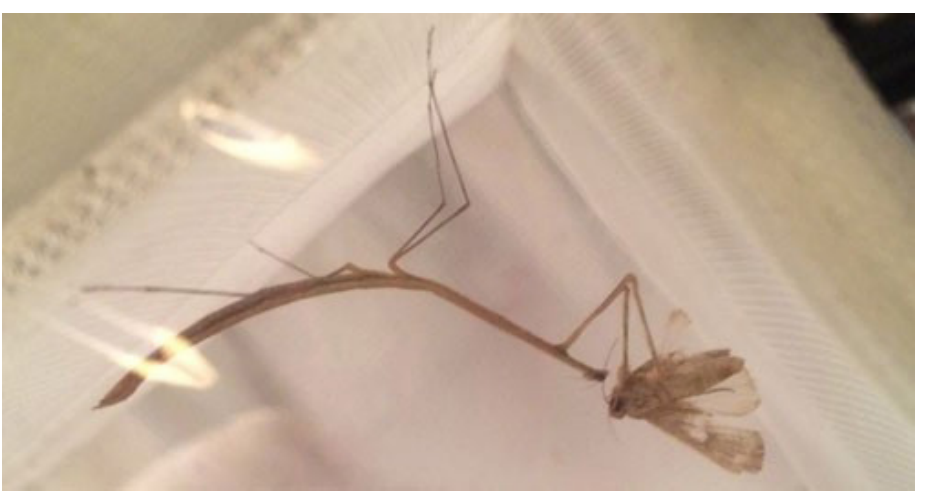

Figure 9. This captive adult female Thesprotia graminis (Scudder) readily fed on medium sized moths and large flies. She often caught food and fed while hanging upside down in the cage.

Credits: Bethany McGregor, UF/IFAS

\section{Habitat}

Members of this species have been documented in various habitat types. Despite its common name, this species is not restricted to grasslands. Specimens have been recorded from pine stands, thickets, and Spanish moss (Tillandsia usneoides) present on an oak tree (Hughes-Schrader 1953). A superficial resemblance to pine needles renders them well camouflaged in areas with fallen pine needles (Helfe 1953).

\section{Economic Importance}

Thesprotia graminis, like other members of the order Mantodea, is predatory. These insects consume other arthropods throughout all life stages and do not consume plant material (Preston-Mafham 1990). Mantid oothecae of various species are commercially available to homeowners and gardeners for raising these insects and releasing them into gardens to prey on destructive pests. However, mantids can predate both beneficial and destructive insects alike, including potentially important or desirable pollinators (Whitfield and Purcell 2014). Grass mantid oothecae are not often found for sale.

\section{Collection}

This species can be collected using a sweep net on vegetation in areas where it is known to occur. The most productive habitats include grassy areas, or locations with a high density of pine needles, both of which are frequented by this mantid species because of the cover they provide (Helfer 1953). If spotted on vegetation, this species can easily be collected by hand, especially the wingless females. They can also be collected using light traps; however, this is only effective for winged males because females are flightless (Rivera 2010).

\section{Selected References}

Costa-Pereira R, Martins FI, Sczesny-Moraes EA, Brescovit A. 2010. Predation on young treefrog (Osteocephalus taurinus) by arthropods (Insecta, Mantodea and Arachnida, Araneae) in Central Brazil. Biota Neotropical 10: 469-472.

Helfer JR. 1953. How to Know the Grasshoppers, Cockroaches, and their Allies. WM. C. Brown Company Publishers: Dubuque, IA.

Holwell GI. 2006. Spermatophore feeding and mating behavior in praying mantises (Mantodea: Liturgusidae). Journal of Zoology 271: 255-260.

Hughes-Schrader S. 1953. Supplementary notes on the cyto-taxonomy of mantises (Orthoptera: Mantoidea). Chromosoma 6: 79-90.

Patel S, Singh G, Singh R. 2016. A checklist of global distribution of Liturgusidae and Thespidae (Mantodea: Dictyoptera). Journal of Entomology and Zoology Studies 4: 793-803.

Peck SB, Beninger C. 1989. A survey of insects of the Florida Keys: Cockroaches (Blattodea), mantises 
(Mantodea), and walkingsticks (Phasmatodea). Florida

Entomologist 72: 612-617.

Preston-Mafham K. 1990. Grasshoppers and mantises of the world. Blandford: London.

Rehn JAG, Hebard M. 1904. The Orthoptera of Thomas County, Georgia, and Leon County, Florida. Proceedings of the Academy of Natural Sciences of Philadelphia 56:

774-802.

Rehn JAG, Hebard M. 1914. On the Orthoptera found on the Florida Keys and in extreme southern Florida. II. Proceedings of the Academy of Natural Sciences of Philadelphia 66: 373-412.

Rehn JAG, Hebard M. 1914. Records of Dermaptera and Orthoptera from west central and southwestern Florida, collected by William T. Davis. Journal of the New York Entomological Society 22: 96-116.

Rivera JA. 2010. A historical review of praying mantis taxonomy and systematics in the Neotropical region: State of knowledge and recent advances (Insecta: Mantodea). Zootaxa 2638: 44-64.

Rondon AAA, Lombardo F, Jantsch LJ. 2007. Checklist of the Neotropical mantises (Insecta, Dictyoptera, Mantodea) Biota Colombiana 8: 105-158.

Scudder SH. 1877. The Florida Orthoptera collected by Mr. J.H. Comstock. Proceedings of the Boston Society of Natural History 19: 80-94.

USA Mantis. Grass mantis (Thesprotia graminis). Photo retrieved from: http://usamantis.com/grassmantis_photo. html

Whitfield JB, Purcell III AH. 2014. Daly and Doyen's Introduction to Insect Biology and Diversity, 3rd Ed. Oxford University Press: New York, NY.

Yager DD. 1990. Sexual dimorphism of auditory function and structure in praying mantises (Mantodea; Dictyoptera). Journal of Zoology 221: 517-537. 